\title{
Investigation on the Printed CNT-Film-Based Electrochemical Sensor for Detection of Liquid Chemicals
}

\author{
Jaeha Noh ${ }^{1} \oplus$, Sangsu An ${ }^{1}$, Changhan Lee ${ }^{1}$, Jiho Chang ${ }^{1, *}$, Snagtae Lee ${ }^{2}$, Moonjin Lee ${ }^{3} \mathbb{D}$ and Dongmin Seo ${ }^{3}$ \\ 1 Major of Electronic Materials Engineering, Korea Maritime and Ocean University, Busan 49112, Korea; \\ jaeha_noh@g.kmou.ac.kr (J.N.); sangsu_an@g.kmou.ac.kr (S.A.); dgks114@g.kmou.ac.kr (C.L.) \\ 2 Department of Offshore Plant Management, Korea Maritime and Ocean University, Busan 49112, Korea; \\ sangtae@kmou.ac.kr \\ 3 Maritime Safety and Environmental Research Division, Korea Research Institute of Ships and Ocean \\ Engineering (KRISO), Daejeon 34103, Korea; moonjin.lee@kriso.re.kr (M.L.); dseo@kriso.re.kr (D.S.) \\ * Correspondence: jiho_chang@kmou.ac.kr
}

Citation: Noh, J.; An, S.; Lee, C.; Chang, J.; Lee, S.; Lee, M.; Seo, D. Investigation on the Printed CNT-Film-Based Electrochemical Sensor for Detection of Liquid Chemicals. Sensors 2021, 21, 5179. https://doi.org/10.3390/s21155179

Academic Editors: Arif Ul Alam and M. Jamal Deen

Received: 18 July 2021

Accepted: 29 July 2021

Published: 30 July 2021

Publisher's Note: MDPI stays neutral with regard to jurisdictional claims in published maps and institutional affiliations.

Copyright: (c) 2021 by the authors. Licensee MDPI, Basel, Switzerland. This article is an open access article distributed under the terms and conditions of the Creative Commons Attribution (CC BY) license (https:/ / creativecommons.org/licenses/by/ $4.0 /)$.

\begin{abstract}
We studied electrochemical sensors using printed carbon nanotubes (CNT) film on a polyethylene telephtalate (PET) substrate. The mechanical stability of the printed CNT film (PCF) was confirmed by using bending and Scotch tape tests. In order to determine the optimum sensor structure, a resistance-type PCF sensor (R-type PCF sensor) and a comb-type PCF sensor (C-type PCF sensor) were fabricated and compared using a diluted $\mathrm{NH}_{3}$ droplet with various concentrations. The magnitude of response, response time, sensitivity, linearity, and limit of detection (LOD) were compared, and it was concluded that C-type PCF sensor has superior performance. In addition, the feasibility of PCF electrochemical sensor was investigated using 12 kinds of hazardous and noxious substances (HNS). The detection mechanism and selectivity of the PCF sensor are discussed.
\end{abstract}

Keywords: carbon nanotubes (CNT); printed CNT film (PCF); electrochemical sensor; hazardous; noxious substances (HNS)

\section{Introduction}

Research on the sensor for chemical substance detection has become more important in recent years due to growing interest in the environment. Various materials such as semiconductors [1], organic materials [2], and ceramics [3,4] are used for chemical substances sensors. Among them, carbon nanotubes (CNT) have many advantages in sensor applications such as large surface area, excellent mechanical strength, and high electrical conductivity. Kong [5] reported the first result that the resistance of single-walled carbon nanotubes (SWCNTs) changes when exposed to gas molecules. At present, CNT-based sensors have a variety of applications, for example, in environmental monitoring, food, agriculture, and biology fields [6]. Environmental monitoring applications include hazardous and noxious substance (HNS) detection sensors. Rushi et al. [7] reported a field effect transistor (FET)-type sensor using SWCNTs that reacts with gaseous hazardous and noxious substances (HNS) such as benzene $\left(\mathrm{C}_{6} \mathrm{H}_{6}\right)$, toluene $\left(\mathrm{C}_{7} \mathrm{H}_{8}\right)$, and xylenes $\left(\mathrm{C}_{8} \mathrm{H}_{10}\right)$. They have succeeded in detecting those HNS with a concentration below the permissible exposure limit (PEL) provided by the Occupational Safety and Health Administration (OSHA). In addition, environmental sensors for detecting $\mathrm{pH}$ [8] and heavy metal ions [9] have been investigated. Despite these various efforts, research on an electrochemical sensor that can estimate the concentration of HNS in seawater is still insufficient. Note that a vast amount of HNS is transported through the ocean every year, and HNS spill accidents occur. Hence, sensors that can quickly identify liquid HNS mixed in seawater are greatly needed [10].

In this study, we study a liquid chemical sensor using a CNT film to detect the spilled HNS. We investigated the fabrication of CNT film, mechanical properties, and detection 
properties of chemical substances. The performance of a CNT sensor was evaluated with 12 kinds of HNSs. Finally, we considered the possibility of selective detection of HNS. In particular, responses of CNT-based sensors have been attributed to effects arising within the tubes (intra-CNT), effects arising at contact points between tubes (inter-CNT), or effects due to the contact between the tubes and the electrodes (Schottky barrier modulations) [6]. However, it is rather focused on the gas sensing mechanisms; hence, discussion about the liquid sensing mechanism of CNT-based sensors is required.

\section{Materials and Methods}

In this experiment, CNT film (thickness $\sim 50 \mu \mathrm{m}$ ) was fabricated by applying the casting method [11]. Thick polyethylene telepthalate (PET) substrate $200 \mu \mathrm{m}$ was used. Multi-walled carbon nanotubes (MWCNT) were ultrasonically dispersed using isopropanol (IPA) for $3 \mathrm{~h}$. The PET substrate was cleaned for $10 \mathrm{~min}$ using distilled ionized (DI) water in an ultrasonic bath. We used both styrene butadiene rubber (SBR) and carboxymethyl cellulose (CMC) as binding materials for CNTs, which are well-known binders for carbonbased electrodes. Lim et al. [12] reported the effect of binders on the rheological properties of microstructure formation of a lithium-ion battery anode. They found that the SBR can affect the dispersion of the graphite particles, especially at a low CMC concentration. The mixing ratio of CNT:(SBR + CMC):acetylene black is 78:17:5 [13]. Here, acetylene black was added to improve the conductivity of the PCF. The PCF was dried in air at $90{ }^{\circ} \mathrm{C}$ for $2 \mathrm{~h}$ to remove binder and moisture [13]. The surface shape and thickness of the PCF were analyzed using an optical microscope and a field emission-scanning electron microscope (FE-SEM). Electrical properties were investigated using an I-V sourcemeter (Keithley 2400). The mechanical properties of the PCF were confirmed by bending and Scotch tape tests [14]. The resistance change is defined as $\left[1-\left(R / R_{0}\right)\right] \times 100 \%$, where $R_{0}$ is the reference resistance, $R$ is the resistance in the bending state. We fabricated both $\mathrm{R}$-type and C-type PCF sensors in order to determine the optimum sensor structure. The R-type PCF sensor operates based on the chemiresistance change, while the C-type PCF sensor operates based on the ion transfer between the adjacent electrodes. The sensor response $(\Delta R)$ was defined as the resistance ratio with and without stimulation $\left(\Delta R=R_{S} / R_{0} \times 100 \%\right.$, where the $R_{0}$ is the reference resistance, $R_{S}$ is the resistance in saturation state).

The response of the sensor was confirmed by using 12 kinds of HNS. The HNS used in the experiment and its characteristics are summarized in Table 1 . The required minimum detection concentration was determined based on the reported PEL of each HNS [15]. Finally, the electrochemical detection mechanism and the selectivity of the PCF sensors were discussed.

Table 1. List of 12 kinds of HNS used in this experiment.

\begin{tabular}{|c|c|c|c|c|c|c|}
\hline Polarity & Substances & $\begin{array}{c}\text { Permeable } \\
\text { Exposure Level } * 1 \\
\text { [ppm] }\end{array}$ & Polarity Index *1 & $\begin{array}{c}\text { Physical Property in } \\
\text { Seawater/ } \\
\text { Floating [F], } \\
\text { Solubility [S], } \\
\text { Evaporating [E] }\end{array}$ & $\begin{array}{c}\text { Limit of } \\
\text { Detection } * 2 \\
\text { [ppm] }\end{array}$ & $\begin{array}{l}\text { Response Time }{ }^{* 2} \\
\text { (Standard Error) [s] }\end{array}$ \\
\hline \multirow{5}{*}{ Polar } & Methyl alcohol & 200 & 6.6 & {$[\mathrm{~F}],[\mathrm{S}]$} & 0.54 & $78( \pm 5)$ \\
\hline & Ethyl alcohol & 200 & 5.2 & {$[\mathrm{~F}],[\mathrm{S}]$} & 0.12 & $98( \pm 8)$ \\
\hline & Iso-propanol & 200 & 4.3 & {$[\mathrm{~F}],[\mathrm{S}],[\mathrm{E}]$} & 0.07 & $82( \pm 8)$ \\
\hline & Acetone & 500 & 5.4 & {$[\mathrm{~F}],[\mathrm{S}],[\mathrm{E}]$} & 2.49 & $107( \pm 9)$ \\
\hline & Ammonia & 25 & 3.8 & {$[\mathrm{~F}],[\mathrm{S}],[\mathrm{E}]$} & 0.01 & $87( \pm 4)$ \\
\hline \multirow{7}{*}{ Non-Polar } & Vinyl acetate & 10 & 2.8 & {$[\mathrm{~F}],[\mathrm{S}],[\mathrm{E}]$} & 3.45 & $187( \pm 5)$ \\
\hline & Benzene & 0.5 & 2.3 & {$[\mathrm{~F}],[\mathrm{E}]$} & 0.07 & $173( \pm 11)$ \\
\hline & Ethyl Benzene & 100 & 2.4 & {$[\mathrm{~F}],[\mathrm{E}]$} & 1.53 & $148( \pm 4)$ \\
\hline & Styrene & 20 & 2.5 & {$[\mathrm{~F}],[\mathrm{E}]$} & 6.39 & $168( \pm 8)$ \\
\hline & Toluene & 50 & 2.3 & {$[\mathrm{~F}],[\mathrm{E}]$} & 0.22 & $159( \pm 8)$ \\
\hline & Heptane & 400 & 0.2 & {$[\mathrm{~F}],[\mathrm{E}]$} & 1.06 & $242( \pm 7)$ \\
\hline & n-Hexane & 50 & 0.3 & {$[\mathrm{~F}],[\mathrm{E}]$} & 10.9 & $217( \pm 11)$ \\
\hline
\end{tabular}

${ }^{* 1}$ reference $[10,15,16] .{ }^{* 2}$ experimental results of this study. 


\section{Results and Discussion}

\subsection{Structure and Electrical Properties of the Fabricated PCF}

Figure 1a is a picture of C-type PCF fabricated on a PET substrate. The thickness of the PCF is $50 \mu \mathrm{m}$. The width of the electrode is $2 \mathrm{~mm}$, and the inter-electrode spacing is $1 \mathrm{~mm}$. Figure $1 \mathrm{~b}$ is the FE-SEM image of PCF surface. CNT bundles and binders can be seen, and it has a large surface area for sensing. Figure $1 \mathrm{c}$ shows the current-voltage characteristics of R-type PCF and C-type PCF. From the current-voltage measurement, the resistance of the R-type and C-type PCFs were $218 \Omega$ and $330 \Omega$, respectively. Figure $1 \mathrm{~d}$ shows the Raman spectra of PCFs. A $532 \mathrm{~nm}$ laser line was used, and a typical Raman spectrum with the well-known MWCNT related peaks at $1580 \mathrm{~cm}^{-1}$ (G-band) and $1336 \mathrm{~cm}^{-1}$ (D-band) were observed [17].
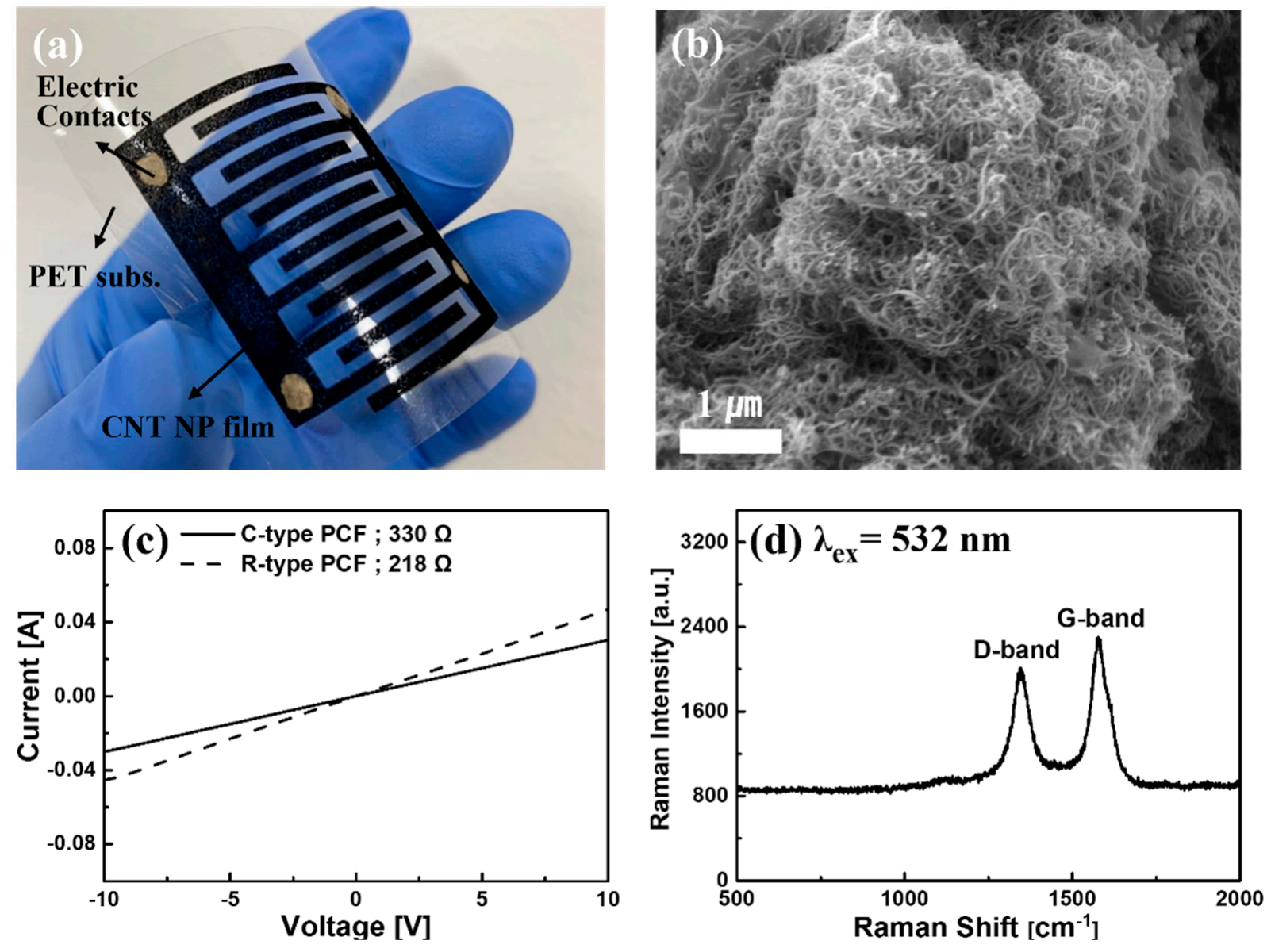

Figure 1. (a) CNT film printed on a PET substrate, (b) FE-SEM image of PCF surface, (c) I-V test results of C-Type and R-type PCFs, and (d) Raman spectra of PCF.

\subsection{Mechanical Properties of PCF}

Figure 2 shows the mechanical properties of PCF. Generally, bending and adhesion (so-called 'Scotch tape test') tests are carried out for the application of films on flexible substrates [18]. Figure 2a shows the resistance change with respect to the change of the bending radius. During the bending test within a radius from 0 to $30 \mathrm{~mm}$ in both inner and outer directions, the PCF shows a small resistance change $(<4.3 \%)$. It is comparable with the previous result. Saran et al. [19] have reported a small resistance change of $<3 \%$ from a bending test of $35 \mu \mathrm{m}$ thick CNT film. Figure $2 \mathrm{~b}, \mathrm{c}$ reveal the before and after test FE-SEM images of PCF. Considerable change in morphology was not observed by the test. 

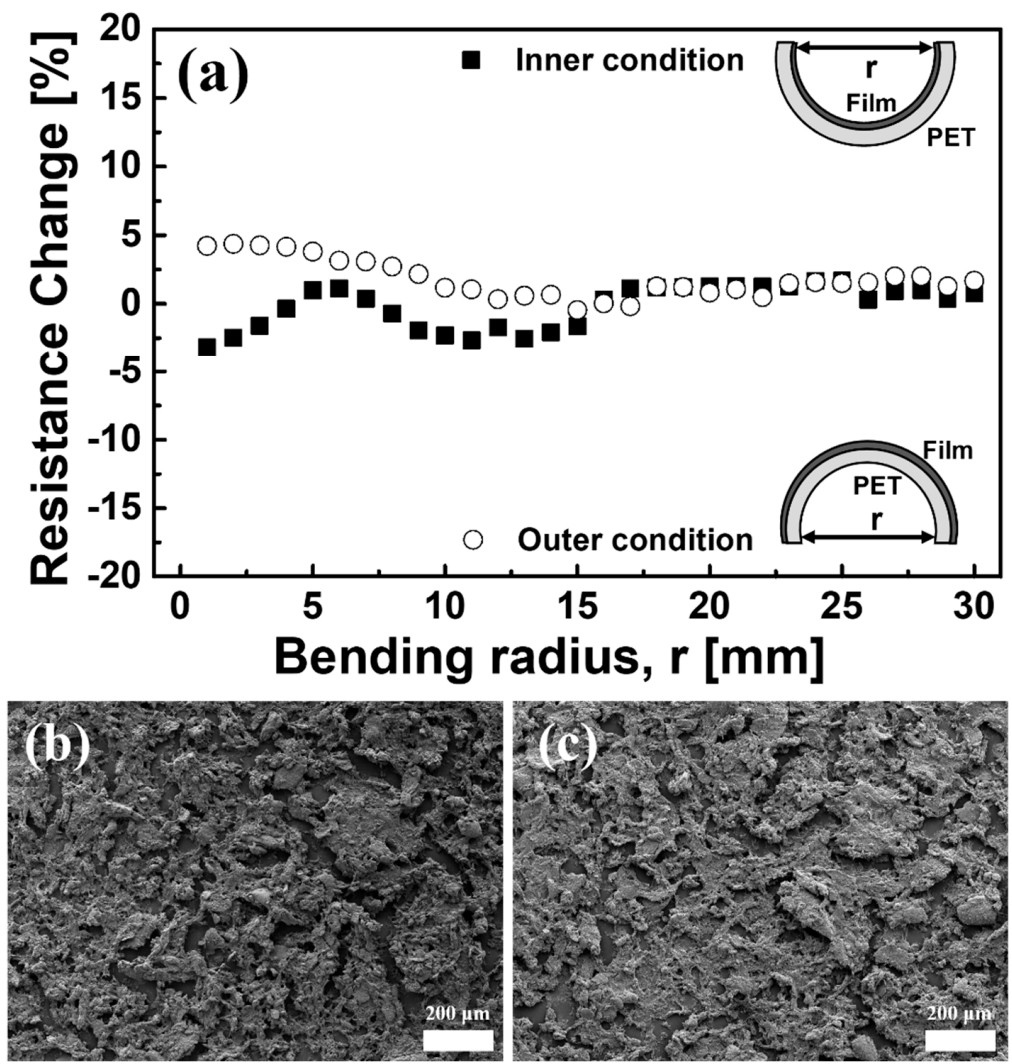

Figure 2. (a) Bending test result of PCF. The resistance change is calculated by: $\left[1-\left(\mathrm{R} / \mathrm{R}_{0}\right)\right] \times 100(\%)$; (b) SEM morphology of pristine PCF, (c) SEM morphology after bending test of PCF.

Figure 3a,b are the Scotch tape test [20] results. No pretreatment of the PET surface [21] to increase the adhesion of the film was performed. Along with the definition, the surface of PCF was scratched using a surgical blade. The scratched surface (Figure 3a) and the surface after attaching and removing the Scotch tape (Figure 3b) were observed by using an optical microscope. The adhesiveness of PCF was judged as excellent at level-4. It can be attributed to the structural properties of the CNT, which is known as the structural interlocking effect [22]. Zhang et al., found that the interfacial shearing strength of a composite film with an epoxy matrix and a CNT improves due to an interfacial interlocking effect of CNTs, which indicates the CNTs act as the core of nucleation. Similar effects were observed from Ag/CNT composite film [22] and carbon fiber/CNT film [23].
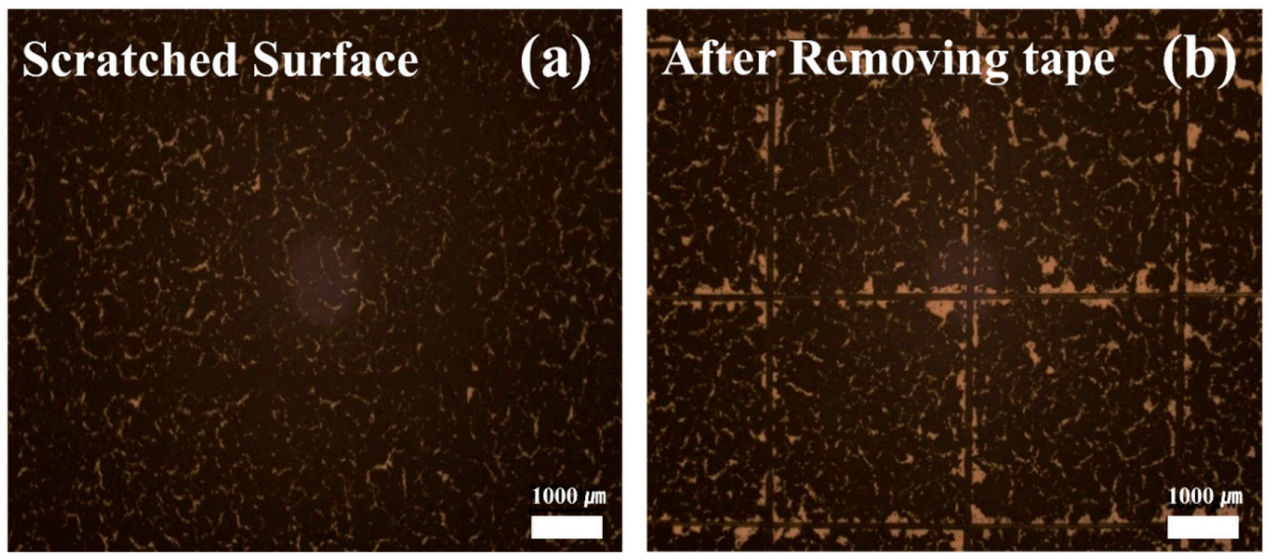

Figure 3. (a) Scratched surface of PCF and (b) PCF surface after removing the scotch tape. Note that the adhesion of PCF is evaluated through the peeled area of the surface. 


\subsection{Temporal Response and Detection Mechanism of PCF Sensors}

After investigating the mechanical strength of the PCF, the sensing properties of the PCF was observed. Figure 4 shows the response of each sensor. A chemical solution was applied, prepared by mixing salt-water $(3.5 \mathrm{wt} \% \mathrm{NaCl})$ and $\mathrm{NH}_{3}(99 \%, \mathrm{NH} 4 \mathrm{OH})$. Note that OSHA has specified a PEL of $\mathrm{NH}_{3}$ as $25 \mathrm{ppm}$. Hence, we performed the experiment in the range of 1 50 ppm. Figure $4 \mathrm{a}, \mathrm{b}$ show the response of both C-type and R-type PCF sensors, in which the inset of each figure is a photograph of the corresponding sensor. A resistance change according to the $\mathrm{NH}_{3}$ concentration was clearly observed. Figure $4 \mathrm{c}, \mathrm{d}$ shows the concentration dependency of sensor response. From the results of Figure 4, sensor performances at room temperature such as sensitivity, LOD, response time, and linearity were summarized in Table 2, although the sensing performance of the PCF sensor was not optimized yet.
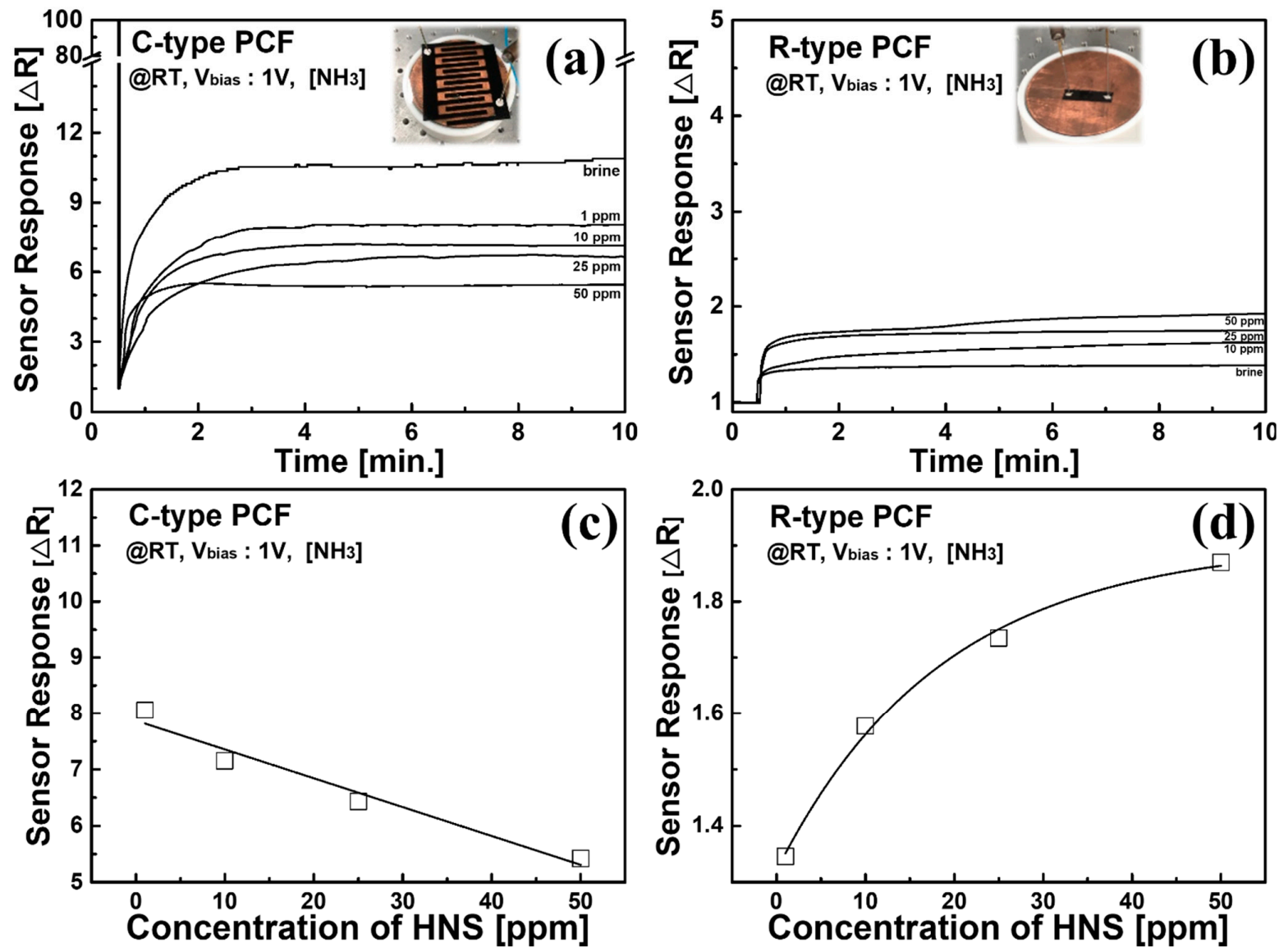

Figure 4. Temporal response of (a) C-type PCF and (b) R-type PCF sensors. Moreover, the sensitivity of (c) C-type and (d) R-type PCF sensors.

Table 2. Sensor performances of both C-type and R-type PCF sensors.

\begin{tabular}{ccc}
\hline Sensor Performances & C-Type PCF & R-Type PCF \\
\hline Sensor Response, $\Delta \mathrm{R}$ at $25 \mathrm{ppm}$ & 6.43 & 1.73 \\
(Standard Error) & $( \pm 0.29)$ & $( \pm 0.14)$ \\
Sensitivity $\left(\Delta \mathrm{R} / \Delta \mathrm{C}_{\mathrm{HNS}}\right)[/ \mathrm{ppm}]$ & 0.053 & 0.011 \\
(Standard Error) & $( \pm 0.003)$ & $( \pm 0.001)$ \\
Limit of Detection $(\mathrm{LOD})[\mathrm{ppm}]$ & 0.011 & 0.025 \\
Response Time, $\tau_{\mathrm{R}}$ at $25 \mathrm{ppm}[\mathrm{s}]$ & 87 & 31 \\
(Standard Error) & $( \pm 4)$ & $( \pm 1.4)$ \\
Coefficient of determination $\left(\mathrm{R}^{2}\right)$ for a linear fitting & 0.96 & 0.88 \\
\hline
\end{tabular}


The experimentally confirmed LOD was $1 \mathrm{ppm}$ for C-type and 10 ppm for R-type PCF sensor, while the LOD [24] of the sensors also can be defined theoretically by the following formula.

$$
\text { Limit of Detection }=3 \frac{\mathrm{S}}{\mathrm{m}}
$$

where $S$ is the standard deviation of the blank measurements and $m$ is the slope of the calibration curve. By applying this formula, the LOD values of the C-type and R-type PCF sensors were calculated to be $0.011 \mathrm{ppm}$ and $0.025 \mathrm{ppm}$. There were several reports about $\mathrm{NH}_{3}$ detection using $\mathrm{CNT}$ sensors. Huh et al., reported the detection of 5 ppm $\mathrm{NH}_{3}$ gas at $300{ }^{\circ} \mathrm{C}$ by a screen-printed SWCNT sensor [25]. They reported that saturation behavior was observed from $40 \mathrm{ppm}$. Wang et al., reported the detection of 5 200 ppm of $\mathrm{NH}_{3}$ at room temperature through MWCNT film produced by CVD (chemical vapor deposition) [26]. They found that the conductance of the sensors decreases when the sensors were exposed in $\mathrm{NH}_{3}$ due to the phase change of CNTs from metallic to semiconducting state. Note that both experimental and theoretical LOD values of those earlier experiments are comparable with the reported values in our experiment. For the purpose of comparison, it is worth mentioning that a tin dioxide-polyaniline nanocomposite flexible sensor revealed an ability to detect low $\mathrm{NH}_{3}$ concentrations of 10-200 ppb [27]. It is expected that improved performance can be obtained by optimizing device structure or/and introduction of catalysts.

The response time of the C-type PCF sensor at 25 ppm $\mathrm{NH}_{3}$ was $87 \mathrm{~s}$, while it was $31 \mathrm{~s}$ for the R-type PCF sensor. Although C-type PCF sensor has a slow response time, it reveals a larger response, lower LOD level, and more linear response than the R-type PCF sensor. Therefore, we concluded that the C-type PCF sensor is more suitable for a liquid chemical sensor to detect HNS diluted in seawater.

The detection mechanism of the C-type PCF sensor is considered. The resistance of the C-type PCF can be explained by the charge transfer rate between electrodes. The charge transfer is determined by the mass transfer by diffusion and can be expressed by the following equation [28].

$$
\mathrm{i}_{\mathrm{d}}=\frac{\mathrm{nFAD}_{0}^{1 / 2} \mathrm{C}_{0}}{\sqrt{\pi \mathrm{t}}},
$$

where $i_{d}$ is the diffusion current, $n$ is the number of reaction electrons, $F$ is the Faraday constant, $A$ is the area of the electrode, $D_{0}$ is the diffusion coefficient, and $C_{0}$ is the initial concentration of redox species. If the measurement principle of chronoamperometry is applicable to the results of this experiment, it will be proportional to $\mathrm{C}_{0}$ and decrease in proportion to $t^{-1 / 2}$, which can be confirmed by plotting the Anson plot as shown in Figure 5. It can be interpreted that the response is determined in proportion to the concentration $\left(\mathrm{C}_{0}\right)$ of HNS. Furthermore, the increase in slope at the high concentration range can be attributed to the structural effect of sensor.

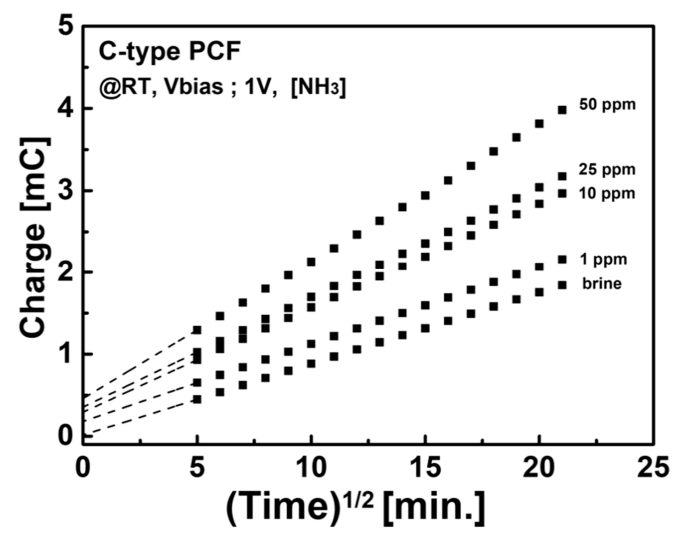

Figure 5. Anson plot of C-type PCF Sensor. Charge transfer corresponds with $\mathrm{NH}_{3}$ concentration. 


\subsection{Chemical Detection Properties of C-Type PCF Sensor}

We have investigated the detection of various HNSs using the C-type PCF sensor. Twelve kinds of HNS were chosen as listed in Table 1. Figure 6 shows three selected results about the iso-propanol (IPA), ethanol (EtOH), and methanol (MeOH) which have PELs of $200 \mathrm{ppm}$ [14]. We varied the concentration of each HNS from 1 to $400 \mathrm{ppm}$. Experimental LOD for $\mathrm{EtOH}$ was $10 \mathrm{ppm}$, while it was $1 \mathrm{ppm}$ for $\mathrm{MeOH}$ and IPA. The other sensor properties such as theoretical LOD and the response time at the PEL are also summarized in Table 1. In this experiment, styrene showed the highest theoretical LOD value of $6.39 \mathrm{ppm}$. In addition, heptane revealed the slowest response time of $242 \mathrm{~s}$. It is clearly shown that the C-type PCF sensor is very feasible for detecting various HNSs diluted in seawater.

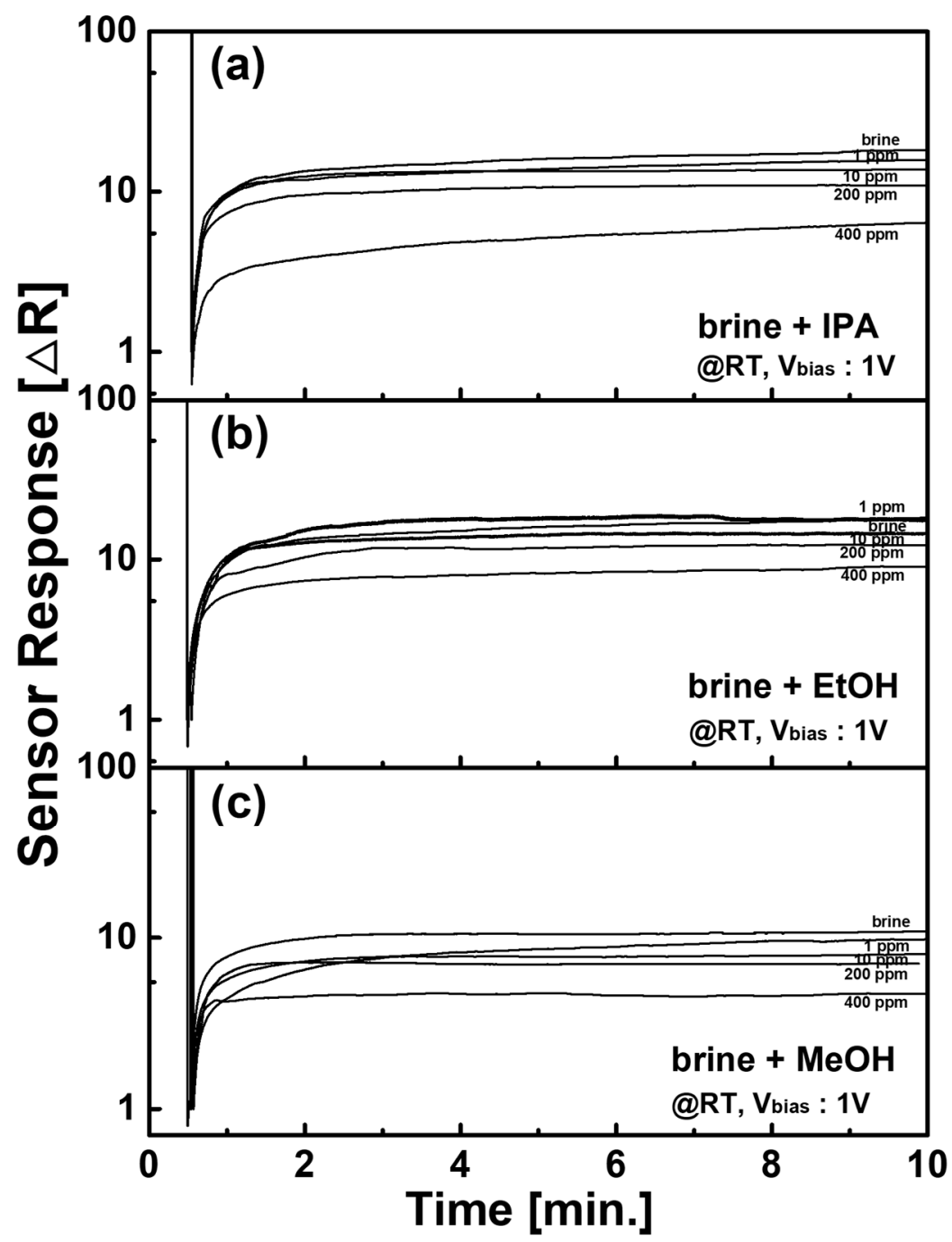

Figure 6. Temporal response of C-type PCF sensor against (a) IPA, (b) EtOH, and (c) $\mathrm{MeOH}$ in brine.

It is well known that not only high sensitivity but also the selectivity of the sensor is an important factor for the development of sensors. The correlation between the response of the sensor and the physical properties of HNS has been considered, as shown in Figure 7. Figure 7a shows the correlation between the sensor responses and the polarity index of HNS. The coefficient of determination $\left(\mathrm{R}^{2}\right)$ from a linear fitting was as low as 0.55 . Figure $7 \mathrm{~b}$ shows the correlation between response time and polarity index. In this case, $\mathrm{R}^{2}$ was 0.83 , which indicates that response time is more strongly correlated with the polarity index. Moreover, note that non-polar HNS showed a longer response time ( $>140 \mathrm{~s})$, while polar HNSs revealed a shorter response time $(<110 \mathrm{~s})$. It can be explained in terms of the difference in the diffusion coefficients of each HNS [29,30]. It is interesting to note that 
the risk index of non-polar HNS is generally higher than that of polar HNS [16]; hence, one could use the difference response time as a guide of warning high-risk HNS. Murad reported that external electric fields on the ion mobility, drift velocity, and drift-diffusion rate of ions. In our experiment, the external field was fixed to $1 \mathrm{~V}$, and the effect of the field is much less dramatic in water than the ions; hence, ionic concentration will dominate the drift velocity and diffusion rate [31].

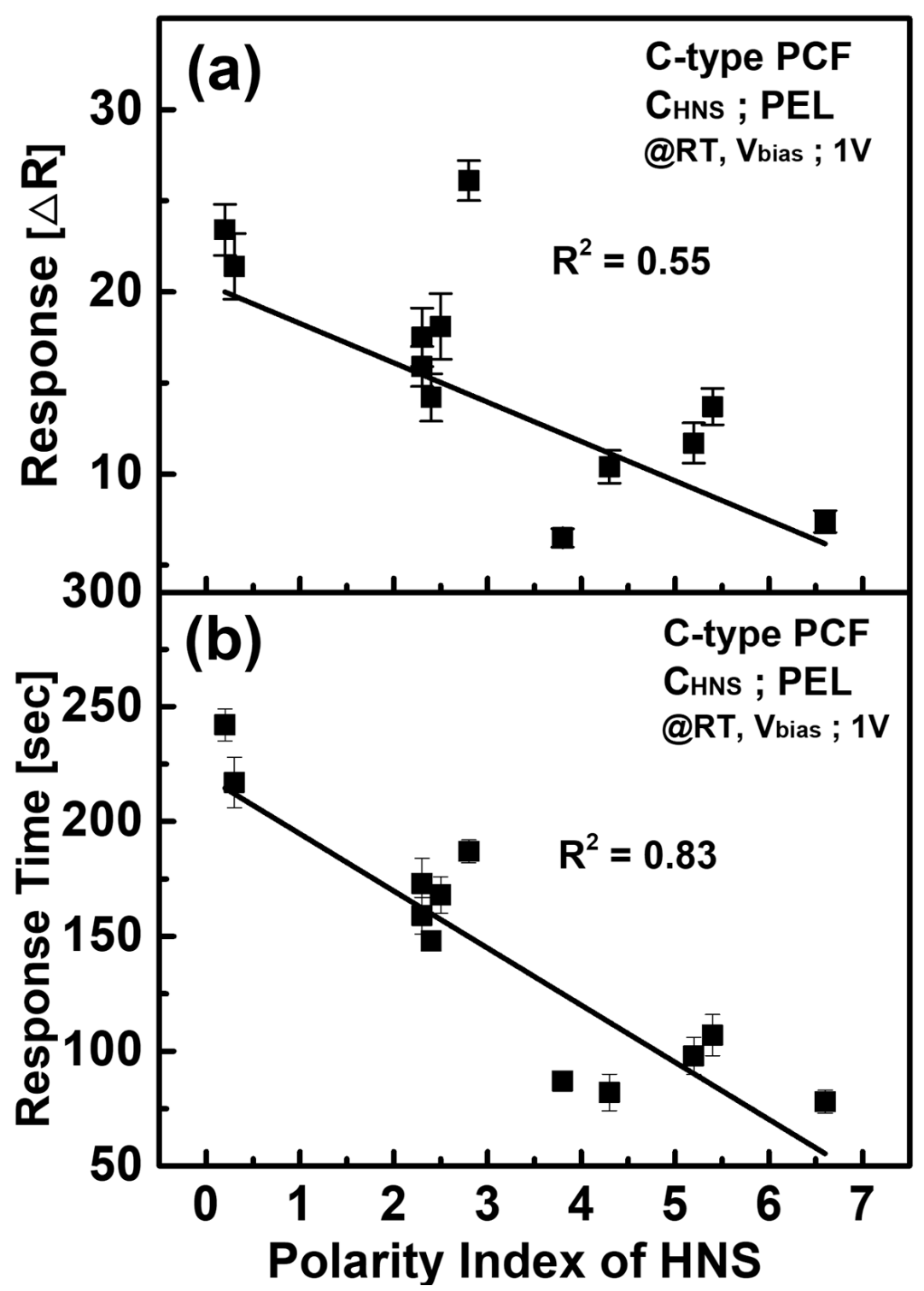

Figure 7. (a) Response and (b) response time characteristics of the C-type PCF sensor according to the polarity index.

\section{Conclusions}

In this study, we have investigated the fabrication and performances of PCF-based electrochemical sensor. The mechanical and electrical properties of the PCF were evaluated. Furthermore, R-type and C-type PCF sensors were fabricated and compared to determine the optimum sensor. C-type PCF sensor was selected, and it was applied for the detection of 12 kinds HNSs. It successfully detected all HNSs at the concentrations below PEL. The possibility of selecting polar and non-polar HNS was confirmed. In conclusion, it was shown that the C-type PCF sensor is feasible as an electrochemical sensor for detecting diluted HNS in seawater. 
Author Contributions: Conceptualization, J.N. and J.C.; methodology, J.N., S.A., C.L. and J.C.; software, J.N.; validation, J.N. and J.C.; formal analysis, J.N. and J.C.; investigation J.N.; resources S.L., M.L. and D.S.; data curation, J.N.; writing—original draft, J.N.; writing—review and editing, J.N., S.A., C.L. and J.C.; visualization, J.N.; supervision, J.C.; project administration, J.C.; funding acquisition, M.L. and D.S. All authors have read and agreed to the published version of the manuscript.

Funding: This research was funded by the Ministry of Oceans and Fisheries, Korea, grant number (D11502119H480000120).

Institutional Review Board Statement: Not applicable.

Informed Consent Statement: Not applicable.

Data Availability Statement: The data presented in this study are available on request from the corresponding author. The data are not publicly available due to privacy restrictions.

Acknowledgments: This research was a part of the project titled "Development of Management Technology for HNS Accident", funded by the Ministry of Oceans and Fisheries, Korea (D11502119H480000120).

Conflicts of Interest: The authors declare no conflict of interest.

\section{References}

1. Hong, S.; Hong, Y.; Jeong, Y.; Jung, G.; Shin, W.; Park, J.; Lee, J.H. Improved CO gas detection of Si MOSFET gas sensor with catalytic Pt decoration and pre-bias effect. Sens. Actuators B Chem. 2019, 300, 127040. [CrossRef]

2. Chen, W.; Yang, P.; Shen, W.; Zhu, C.; Lv, D.; Tan, R.; Song, W. Flexible room temperature ammonia gas sensor based on in suit polymerized PANI/PVDF porous composite film. J. Mater. Sci. Mater. Electron. 2020, 31, 11870-11877. [CrossRef]

3. Tonezzer, M. Selective gas sensor based on one single $\mathrm{SnO}_{2}$ nanowire. Sens. Actuators B Chem. 2019, 288, 53-59. [CrossRef]

4. Zhou, J.Y.; Bai, J.L.; Zhao, H.; Yang, Z.Y.; Gu, X.Y.; Huang, B.Y.; Xie, E.Q. Gas sensing enhancing mechanism via doping-induced oxygen vacancies for gas sensors based on indium tin oxide nanotubes. Sens. Actuators B Chem. 2018, 265, 273-284. [CrossRef]

5. Kong, J. Nanotube Molecular Wires as Chemical Sensors. Science 2000, 287, 622-625. [CrossRef] [PubMed]

6. Schroeder, V.; Savagatrup, S.; He, M.; Lin, S.; Swager, T.M. Carbon Nanotube Chemical Sensors. Chem. Rev. 2018, 119, $599-663$. [CrossRef]

7. Rushi, A.D.; Datta, K.P.; Ghosh, P.S.; Mulchandani, A.; Shirsat, M.D. Selective Discrimination among Benzene, Toluene, and Xylene: Probing Metalloporphyrin-Functionalized Single-Walled Carbon Nanotube-Based Field Effect Transistors. J. Phys. Chem. C 2014, 118, 24034-24041. [CrossRef]

8. Li, P.; Martin, C.M.; Yeung, K.K.; Xue, W. Dielectrophoresis Aligned Single-Walled Carbon Nanotubes as pH Sensors. Biosensors 2011, 1, 23-35. [CrossRef]

9. Gumpu, M.B.; Sethuraman, S.; Krishnan, U.M.; Rayappan, J.B.B. A review on detection of heavy metal ions in water-An electrochemical approach. Sens. Actuators B Chem. 2015, 213, 515-533. [CrossRef]

10. Kim, Y.R.; Kim, T.W.; Son, M.H.; Oh, S.W.; Lee, M.J. A study on prioritization of HNS management in Korean waters. J. Korean Soc. Mar. 2015, 21, 672-678. [CrossRef]

11. Bodnarchuk, M.I.; Kovalenko, M.V.; Pichler, S.; Fritz-Popovski, G.; Hesser, G.; Heiss, W. Large-Area Ordered Superlattices from Magnetic Wüstite/Cobalt Ferrite Core/Shell Nanocrystals by Doctor Blade Casting. ACS Nano 2009, 4, 423-431. [CrossRef]

12. Lim, S.; Kim, S.; Ahn, K.H.; Lee, S.J. The effect of binders on the rheological properties and the microstructure formation of lithium-ion battery anode slurries. J. Power Sources 2015, 299, 221-230. [CrossRef]

13. Prosini, P.P.; Cento, C.; Carewska, M.; Masci, A. Electrochemical performance of Li-ion batteries assembled with water-processable electrodes. Solid State Ion. 2015, 274, 34-39. [CrossRef]

14. Lee, S.W.; Kim, K.K.; Cui, Y.; Lim, S.C.; Cho, Y.W.; Kim, S.M.; Lee, Y.H. Adhesion test of Carbon Nanotube Film coated onto transparent conducting substrates. Nano 2010, 5, 133-138. [CrossRef]

15. Kim, Y.R.; Lee, M.; Jung, J.Y.; Kim, T.W.; Kim, D. Initial environmental risk assessment of hazardous and noxious substances (HNS) spill accidents to mitigate its damages. Mar. Pollut. Bull. 2019, 139, 205-213. [CrossRef]

16. Kim, Y.R.; Choi, J.Y.; Son, M.H.; Oh, S.W.; Lee, M.J.; Lee, S.J. Prioritizing noxious liquid substances (NLS) for preparedness against potential spill incidents in Korean coastal waters. J. Korean Soc. Mar. 2016, 22, 846-853. [CrossRef]

17. Alves, A.P.P.; Trigueiro, J.P.C.; Calado, H.D.R.; Silva, G.G. Poly(3-hexylthiophene)-multi-walled carbon nanotube (1:1) hybrids: Structure and electrochemical properties. Electrochem. Acta 2016, 209, 111-120. [CrossRef]

18. Riheen, M.A.; Saha, T.K.; Sekhar, P.K. Inkjet Printing on PET Substrate. J. Electrochem Soc. 2019, 166, B3036-B3039. [CrossRef]

19. Saran, N.; Parikh, K.; Suh, D.-S.; Muñoz, E.; Kolla, H.; Manohar, S.K. Fabrication and Characterization of Thin Films of Single-Walled Carbon Nanotube Bundles on Flexible Plastic Substrates. J. Am. Chem. Soc. 2004, 126, 4462-4463. [CrossRef]

20. Chalker, P.R.; Bull, S.J.; Rickerby, D.S. A review of the methods for the evaluation of coating-substrate adhesion. Mater. Sci. Eng. A 1991, 140, 583-592. [CrossRef]

21. Petit, S.; Laurens, P.; Barthes-Labrousse, M.G.; Amouroux, J.; Aréfi-Khonsari, F. Al/PET adhesion: Role of an excimer laser pretreatment of PET prior to aluminum thermal evaporation. J. Adhes. Sci. Technol. 2003, 17, 353-368. [CrossRef] 
22. Zhang, Y.; Kang, Z.; Bessho, T. Two-component spin-coated Ag/CNT composite films based on a silver heterogeneous nucleation mechanism adhesion-enhanced by mechanical interlocking and chemical grafting. Nanotechnology 2017, 28, 105607. [CrossRef]

23. Zhang, F.-H.; Wang, R.-G.; He, X.-D.; Wang, C.; Ren, L.-N. Interfacial shearing strength and reinforcing mechanisms of an epoxy composite reinforced using a carbon nanotube/carbon fiber hybrid. J. Mater. Sci. 2009, 44, 3574-3577. [CrossRef]

24. Bohari, N.A.; Siddiquee, S.; Saallah, S.; Misson, M.; Arshad, S.E. Optimization and Analytical Behavior of Electrochemical Sensors Based on the Modification of Indium Tin Oxide (ITO) Using PANI/MWCNTs/AuNPs for Mercury Detection. Sensors 2020, 20, 6502. [CrossRef] [PubMed]

25. Quang, N.H.; Van Trinh, M.; Lee, B.-H.; Huh, J.-S. Effect of NH3 gas on the electrical properties of single-walled carbon nanotube bundles. Sens. Actuators B Chem. 2006, 113, 341-346. [CrossRef]

26. Wang, S.G.; Zhang, Q.; Yang, D.J.; Sellin, P.J.; Zhong, G.F. Multi-walled carbon nanotube-based gas sensors for NH3 detection. Diam. Relat. Mater. 2004, 13, 1327-1332. [CrossRef]

27. Li, S.; Liu, A.; Yang, Z.; He, J.; Wang, J.; Liu, F.; Lu, G. Room temperature gas sensor based on tin dioxide@ polyaniline nanocomposite assembled on flexible substrate: Ppb-level detection of $\mathrm{NH}_{3}$. Sens. Actuators B Chem. 2019, 299, 126970. [CrossRef]

28. Yamada, A.; Kato, Y.; Yoshikuni, T.; Tanaka, Y.; Tanaka, N. Computer-assisted measurement of ion-diffusion coefficients by use of the cottrell equation. Anal. Chim. Acta 1979, 112, 55-63. [CrossRef]

29. Taralkar, S.V.; Chattopadhyay, S.; Gaikar, V.G. Parametric optimization and modeling of batch extraction process for extraction of betulinic acid from leaves of Vitex Negundo Linn. Sep. Sci. Technol. 2015, 51, 641-652. [CrossRef]

30. Karimi, M.; Tashvigh, A.A.; Asadi, F.; Ashtiani, F.Z. Determination of concentration-dependent diffusion coefficient of seven solvents in polystyrene systems using FTIR-ATR technique: Experimental and mathematical studies. RSC Adv. 2016, 6, 9013-9022. [CrossRef]

31. Murad, S. The role of external electric fields in enhancing ion mobility, drift velocity, and drift-diffusion rates in aqueous electrolyte solutions. J. Chem. Phys. 2011, 134, 114504. [CrossRef] [PubMed] 